\title{
HSCT FOR CHRONIC LYMPHOCYTIC LEUKEMIA
}

\author{
Carlos Chiattone ${ }^{1,2}$,Vinicius Campos de Molla ${ }^{3,4}$, Ricardo Chiattone ${ }^{2}$,Rodrigo Santucci ${ }^{5,6}$, José Carlos \\ Barros $^{2}$,Celso Arrais s $^{3,4}$
}

1.FCM da Santa Casa de São Paulo - 2.Hospital Samaritano de São Paulo - 3.Hospital Sírio Libanês - 4.Universidade Federal de São Paulo - 5. Hemomed Instituto de Oncologia e Hematologia - 6.Faculdade de Medicina do ABC

\section{INTRODUCTION}

Chronic Lymphocytic Leukemia (CLL), the most common leukemia in adults, is characterized by a clonal expansion of mature B cells that express CD5. It is probably one of the onco-hematological disease that has advanced the most in recent years ${ }^{[1]}$. As usual, therapeutic advancement occurs as a result of progressive biological knowledge of the disease. In this regard, in the last decade, we have learned a lot about its pathogenesis, including the identification of recurrent mutations and the clarification of clonal architectures, analysis of transcriptomes and the several stages of the leukemogenic process. These biological characteristics make it possible to classify a CLL into different risk groups and make the ther-

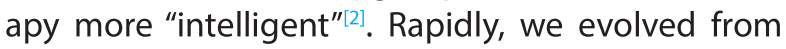
conventional chemotherapy to most effective treatments, such as monoclonal antibodies, especially anti-CD20 of the first and second generations, target drugs that interfere with the signaling pathways of $B$ cell receptors (BTK ${ }^{[3-6]}$ and $\mathrm{PI} 3 \mathrm{~K}$ inhibitors7) and drugs that inhibit anti-apoptotic protein $\mathrm{BCL}-2^{[8,9]}$.

Current treatment strategies include the combination of chemotherapy (chlorambucil, fludarabine and cyclophosphamide, or bendamustine), with anti-CD20 monoclonal antibodies (rituximab or obinutuzumab), BTK inhibitors (ibrutinib and acalabrutinib), the PI3K inhibitor idelalisib, and the anti BCL2 inhibitor, venetoclax. Worldwide, chemoimmunotherapy has progressively lost space for new therapies that show improved response duration and progression-free survival (PFS), in addition to the better profile of adverse events ${ }^{[10]}$. B-cell receptors inhibitors achieve high response rates but are used as a continuous treatment (until progression or intolerance), while BCL-2 inhibitors strategies induce deeper responses and are usually part of finite therapies.
Despite the progress with a significant improvement in progression-free survival with the new agents, CLL remains an incurable disease in most cases. The disease often relapse relatively early and progressively becomes refractory. Besides, in some cases, Richter's transformation occurs and outcome of this serious complication is usually dismal.

Allogeneic hematopoietic stem cell transplant (allo-HSCT) has been used less and less, but it is still an alternative to be discussed, especially in countries where the availability of new drugs is limited. Previous series have demonstrated encouraging results with a progression-free survival (PFS) of around 40$50 \%$ and overall survival (OS) of around $50-60 \%$ at 5 years. ${ }^{[11,12]}$

New alternatives of treatment, such as CAR-T cells, are also being tested for refractory patients after several previous treatment lines, and will be further discussed in this chapter.

\section{WHEN TO PERFORM ALLOGENEIC STEM CELL TRANSPLANT FOR CLL}

In 2007, an EBMT consensus of allo-HSCT for the treatment of high-risk CLL patients was proposed ${ }^{[13]}$. At that time, allo-HSCT became the treatment of choice for this group of patients. However, the treatment of CLL has changed over the last decade due to the development of new and very active agents $8,{ }^{[14,15]}$. However, there are no randomized clinical trials that compare the outcomes of allo-HSCT with conventional chemoimmunotherapy, or novel non-chemotherapy-containing regimens so far.

In this setting, there has being a great paradigm change on who, and especially when, a patient would 
be a suitable candidate to an allo-HSCT. The approval of novel agents has had an impact on the role of allo-HSCT in CLL and, since the approval of ibrutinib, idelalisib, and venetoclax in the United States and Europe, the number of transplants continues to decrease (Figure 1). This trend is likely to continue as other new agents are approved and the existing ap- proved agents are used earlier in the course of the disease 12. The same pattern seems to occur in Brazil, although slower, considering the delay on the approval of the new agents. It is important to note the great heterogeneity of the availability of the new agents in different treatment centers in Brazil, leading to a great variability on the time of transplant indication

FIGURE 1 - Allogeneic hematopoietic stem cell transplant for CLL by year

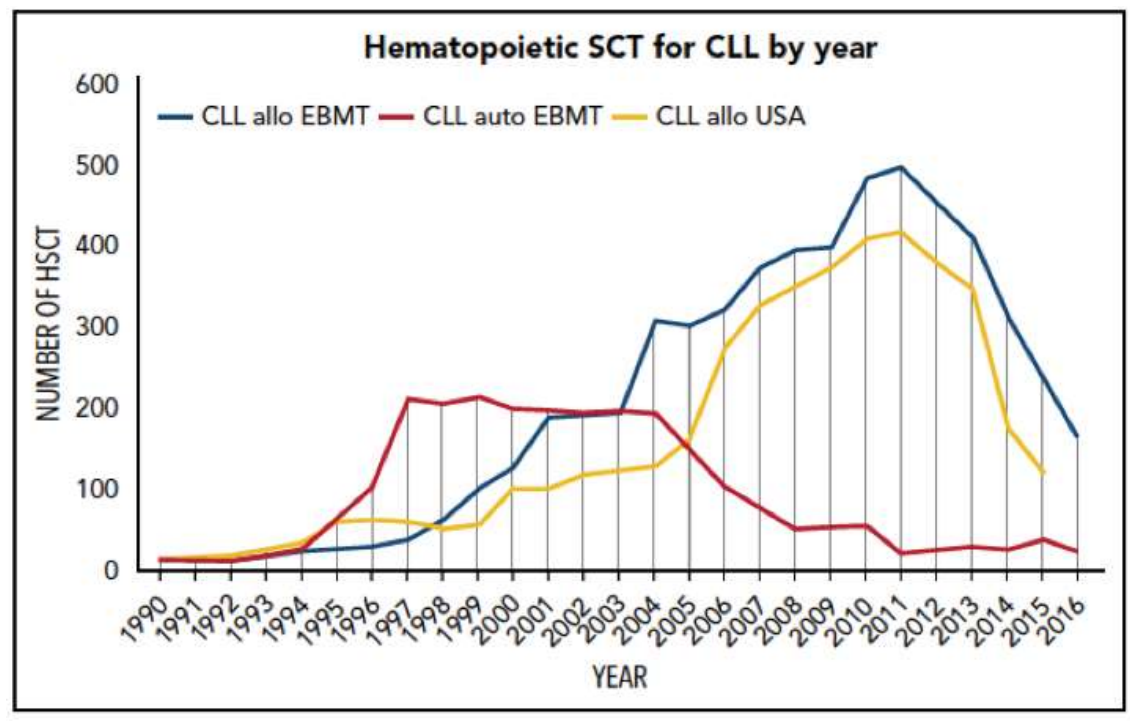

Figure 1. Changing patterns over time of HSCT in CLL in the US and Europe

The Clinical Practice Recommendations for Use of Allogeneic Hematopoietic Cell Transplantation in Chronic Lymphocytic Leukemia of the American Society for Blood and Marrow Transplantation ${ }^{[16]}$ is one of the most comprehensive guidelines on HSCT for CLL. In order to define recommendations regarding the most appropriate time for HSCT for CLL, it is mandatory to describe when in the disease therapy timeline should the HSCT be proposed.

\section{RECOMMENDATIONS}

Patients to be considered for allo-HSCT:

A.Standard Risk CLL (patients without del ${ }^{17} p$ and/or TP53 mutations and/or complex karyotype): when there is lack of response or disease progression after $B C R$ inhibitors or $B C L-2$ inhibitors.

B.For High Risk CLL (patients with del17p and/or TP53 mutations and/or complex karyotype):

1.Patients that experienced objective response to after BCR inhibitors or BCL-2 inhibitors after $2^{\text {nd }}$ line treatment

2.Patients with relapsed / refractory disease after treatment with $\mathrm{BCR}$ inhibitors or BCL-2 inhibitors after 2 nd line treatment
3.Patients experiencing Richter transformation after achieving an objective response to therapy.

The considerations above may depend on the availability of new agents at different Brazilian treatment centers.

In 2018, Dr. John Gribben published recommendations on how and when an allo-HSCT should be performed considering the novel agents including ibrutinib, acalabrutinib, idelalisib, and venetoclax ${ }^{[12]}$. His approach led to the algorithm shown in Figure 2. Patients that require treatment and do not have TP53 mutation are candidates for chemoimmunotherapy or a clinical trial. Those patients with TP53 mutation are candidates for non-chemotherapy regimens with new agents in front line. Patients who are relapsed or refractory can be treated with $B C R$ inhibitors or venetoclax plus rituximab. Patients who relapse or are intolerant to ibrutinib are candidates for venetoclax and those who have failed venetoclax plus rituximab are candidates for ibrutinib. Patients responding to second novel agents can either proceed to allo-HSCT or continue with the novel agent ${ }^{[17]}$. 
FIGURE 2 - Allogeneic hematopoietic stem cell transplant for CLL algorithm

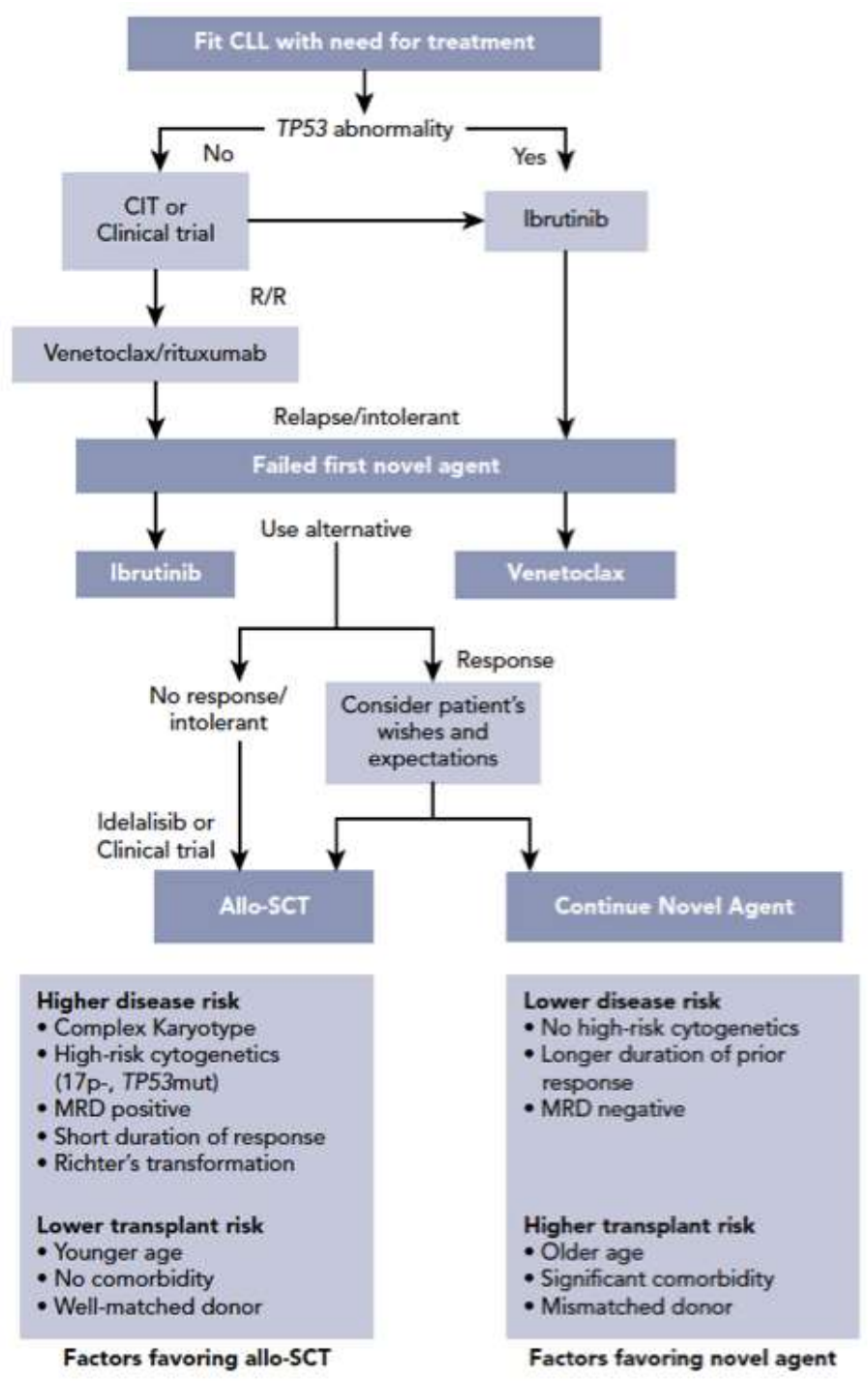

\section{CONDITIONING REGIMEN}

There is no randomized trial comparing different conditioning regimens intensity, although myeloablative conditioning (MAC) proved to be toxic for CLL patients with high rates of transplant-related mortality since most of patients are elderly presenting great toxicity to $M A C^{[18,19]}$.

The reduced intensity conditioning $(\mathrm{RIC})$ appears to be a more adequate regimen intensity for the CLL population. With matched sibling donors (MSD) and matched unrelated donors (MUD) the non-relapsed mortality (NRM), relapse, progression-free survival (PFS) and OS at 5 years was $23 \%, 38 \%, 39 \%$, and $50 \%$, respectively. The cumulative incidence of chronic extensive graft versus host disease (GVHD) was $49 \%$ for MSD and $53 \%$ for MUD. Lymphadenopathy $\geq 5 \mathrm{~cm}$ was associated with a higher risk of relapse at 5 years ( $71 \%$ vs. $27 \%)$, when compared with patients without ${ }^{[20,21]}$. Allo-HSCT may overcome the poor prognosis of these high-risk genetic aberrations, including $17 p$ deletion ${ }^{[22-26]}$.

There is a great variety of conditioning regimens. The most common are: FluBu, FluTBI 200cGy ${ }^{[20,21]}$, FluCy ${ }^{[24-26]}, \mathrm{FCR}^{[27]}$, and $\mathrm{BFR}^{[28]}$, nevertheless, there is no comparative trial between these conditioning regimens.

\section{RECOMMENDATIONS FOR MSD AND MUD:}

A.BFR: rituximab $375 \mathrm{mg} / \mathrm{m}^{2}$ on day -13 , and $100 \mathrm{mg} /$ $\mathrm{m} 2$ on days $-6,+1$ and +8 , fludarabine $30 \mathrm{mg} / \mathrm{m}^{2}$ on days $-5,-4$ and -3 , and bendamustine $130 \mathrm{mg} / \mathrm{m}^{2}$ on days $-5,-4$ and -3 . GVHD prophylaxis with oral cyc- 
losporine (CSP) starting on day -2 , and intravenous methotrexate (MTX) $5 \mathrm{mg} / \mathrm{m}^{2}$ on days $+1,+3$, and + 6. In MUD will receive an additional MTX $5 \mathrm{mg} / \mathrm{m} 2$ on day +11 , and rabbit antithymocyte globulin $1 \mathrm{mg} / \mathrm{kg}$ on days -2 and $-1^{[28]}$.

B.FluTBI 200cGy*: fludarabine $30 \mathrm{mg} / \mathrm{m}^{2}$ on days $-4,-3$ and -2 , and TBI 200 cGy on day -1 . Immunosuppressive therapy starts with CSP on day -3 and oral mycophenolate mofetil (MMF) $15 \mathrm{mg} / \mathrm{kg}$ tid on day $+120,21$. *When rituximab or bendamustine is not available,

Allo-HSCT alternative donors are also good options for CLL. For the haploidentical donors, 2 years PFS and OS were 38 and $48 \%$ respectively ${ }^{[29]}$. Cord blood transplant is also feasible in CLL when sibling ou matched unrelated donors are absent, in a retrospective study the PFS and OS at 3 years were $54 \%$ and $45 \%$, respectively ${ }^{[30]}$.

\section{RECOMMENDATIONS FOR ALTERNATIVES DONORS:}

A.Haploidentical donors. FluCyTBI 400cGy: cyclophosphamide $14.5 \mathrm{mg} / \mathrm{kg}$ on days -7 and -6 , fludarabine $30 \mathrm{mg} / \mathrm{m} 2$ on days -7 to -3 , ant TBI 200cGy on days -2 and -1. GVHD prophylaxis: cyclophosphamide $50 \mathrm{mg} /$ $\mathrm{kg}$ on days +3 and +4 , CSP starting on day +5 until, and oral MMF $15 \mathrm{mg} / \mathrm{kg}$ tid starting on day $+5^{[31,32]}$. Granulocyte-colony stimulating factor (G-CSF) $5 \mathrm{mcg} /$ $\mathrm{kg}$ from day +5 until neutrophil engraftment.

B.Cord blood transplant. FluCyTBI 200cGy: cyclophosphamide $50 \mathrm{mg} / \mathrm{kg}$ on day -6 , fludarabine $40 \mathrm{mg} /$ $\mathrm{m} 2$ on days -6 to -2 , and TBI 200 cGy on day -1 . For GVHD prophylaxis, we recommend CSP starting on day -3 , and oral MMF $1000 \mathrm{mg}$ twice daily from day -3 to day +30 . G-CSF $5 \mathrm{mcg} / \mathrm{kg}$ per day from day 0 until the absolute neutrophil count (ANC) was greater than $2500 / \mathrm{mcL}$ for 2 consecutive measurements ${ }^{[33]}$.

\section{AUTOLOGOUS STEM CELL TRANSPLANTATION}

In trials comparing autologous stem cell transplantation (auto-SCT) with observation, auto-SCT improved event free survival, without benefit in overall survival, and autologous did not overcome the poor prognostic markers, in addition to worse the quality of life ${ }^{34-36}$. Currently, with access to targeted therapies and the small benefit of auto-SCT, this therapy is not routinely indicated in CLL.

\section{MANAGEMENT OF RELAPSE AFTER ALLOGENEIC TRANSPLANTATION FOR CLL}

Treatment of patients with relapsed CLL after allo-HSCT is a challenging unmet clinical need, par- ticularly because patients are often refractory to chemoimmunotherapy before transplantation and, more recently, they might also be also refractory to BTK inhibitors and venetoclax. However, even in this group of high-risk patients, opportunities to achieve long-term survival remain, and the prognosis is not as bad as observed in acute leukemias or aggressive lymphomas, for example. In a retrospective analysis of 52 patients with CLL who relapsed after allo-HSCT, median OS from relapse was 35 months; and the median OS from the time of re-treatment was 21 months ${ }^{[37]}$.

Relapse of CLL after allo-HSCT can be sometimes rescued by immunotherapeutic approaches, such as immunosuppression withdrawal or donor lymphocyte infusion (DLI), not all patients are responsive to these strategies. Such cases could benefit from combinations of monoclonal anti-CD20 antibodies, standard chemotherapy, and especially from targeted agents such as ibrutinib, lenalidomide, and venetoclax $^{[37-43]}$ In addition, promising data have emerged from several studies evaluating the effect of CAR-T cells and, more recently, CAR-NK cells for high-risk and very advanced $\mathrm{CL}^{[44-46]}$

\section{DONOR LYMPHOCYTE INFUSION (DLI) - MRD- DRIVEN STRATEGIES}

A retrospective analysis of the German Group ${ }^{42}$ analyzed 77 consecutive allografted CLL patients for CLL in which immunosuppression tapering and rituximab-augmented donor lymphocyte infusions (DLI) were guided by MRD monitoring. Interventions started at a median of 91 (22-273) days after allo-HSCT, resulting in a probability of being eventfree and MRD-negative 1 year after transplant of $57 \%$. Patients who were event-free and MRD-negative at 12 months had a 4-year PFS of $77 \%$. Relapse incidence post allo-HSCT was $26 \%$ at 3 years and patients who experienced relapse had a survival of $56 \% 2$ years after relapse.

Recently, a joint French Innovative Leukemia Organization (FILO) and Société Francophone de Greffe de Moelle et de Thérapie Cellulaire (SFGM-TC) multicenter phase II trial ${ }^{[47]}$ evaluated prospectively an approach of post-transplantation MRD-driven immune-intervention for CLL that included early CSA tapering (day+90) potentially followed by DLI in case of a post-transplantation MRD positive status or keeping cyclosporine for a longer period for those with a MRD negative status. They observed relatively low rates of chronic GVHD and NRM and a very high rate of overall survival at 3 years (close to $90 \%$ ). MRD negative at 12 months was achieved in $79 \%$ of evalu- 
able patients. In this context of early preemptive immune-intervention, the study failed to show a benefit of DLI to convert MRD from positive to negative, although 3 out of 5 patients who received DLI were already in clinical progression at the time of infusion.

\section{IBRUTINIB}

In 2016, Ryan et al. published results of 27 patients with relapsed CLL following allo-HSCT who subsequently received ibrutinib salvage therapy and achieved an overall response rate of $87.5 \%$, PFS rate at 2 years was $77 \% 40$.

More recently, an EBMT registry-based retrospective multicenter study included patients who underwent allo-HSCT for CLL between September 2002 and December $2015^{[48]}$, and who received ibrutinib after transplantation for disease relapse. Patients in this study received a range of treatments including anti-CD20 monoclonal antibodies, DLIs, lenalidomide, standard chemotherapy and, in a small number of patients, ibrutinib. This study demonstrated that, notwithstanding high-risk disease and multiple lines of prior therapy before allo-HSCT (median 3 lines, range: 1-10), ibrutinib was an effective and tolerable salvage therapy for CLL relapse following allo-HSCT, with an OS rate at 2 years of $72 \%$ and 2-year PFS rate of $50 \%$. Patients with late relapse after allo-HSCT ( $\geq 24$ months) tended to had a superior outcome as compared to those with earlier relapses. Only $30 \%$ of patients achieved $C R$, as expected for a BTK-inhibitor strategy. However, among 11 patients in CR tested for MRD, 5 were negative, showing a possible ibrutinib-mediated GVL effect40, ${ }^{[49,50]}$. At the time of ibrutinib initiation, ten patients had still an active chronic GVHD, all these patients had their GVHD resolved after receiving ibrutinib and only one patient had limited de novo chronic GVHD while on Ibrutinib, with a quick resolution. Ibrutinib is indeed a therapeutic option for steroid-refractory chronic GVHD, being approved for this indication by the FDA ${ }^{[51-53]}$. Ibrutinib was well tolerated with a safety profile similar to the one observed in the overall population of patients with relapsed/refractory CLL treated with ibrutinib3. Based on this analysis, ibrutinib seems to be efficient and safe for CLL relapse after allo-HSCT, and combinations including this agent should be evaluated in larger prospective trials in this scenario.

\section{SECOND ALLO-HSCT}

The availability of new alternative therapies, including both $B C R$ and $B C L 2$ inhibitors have taken the place of a $2^{\text {nd }}$ allo-HSCT in the relapse/refractory setting, either obviating the need for transplant or delaying this strategy until later in the management of the disease. Consequently, the number of $2^{\text {nd }}$ allo-HSCT for CLL has considerably decreased, both in the United States ${ }^{[16]}$ and Europe ${ }^{[47]}$.

\section{CAR-T CELLS}

The first description of CAR-T cells for CLL was a clinical trial of a single infusion of allogeneic anti-CD19CART cells for 10 patients with B-cell malignancies (4 with CLL) that persisted after allo-HSCT and standard DLIs. Three patients achieved durable CRs, including 2 patients with CLL. This approach is associated with significant acute toxicity, especially due to the cytokine release syndrome, but does not represent a risk for GVHD ${ }^{[54]}$.

However, as more patients with CLL were included in trials with CAR-T cells, results became more disappointing. In the 134 highly pre-treated CLL patients treated with CAR-T cells reported to date, the CR rate remains of 20 to $30 \%$, with a median PFS of $18 \%$ at 18 months 55 , and a proportion of the patients have a subsequent relapse at follow-up ${ }^{[4,56,57]}$

More recently, a pilot study evaluated the safety and feasibility of administering ibrutinib concurrently with CD19 CAR T-cell in 19 CLL patients. CD19 CAR T-cell therapy with concurrent ibrutinib was well tolerated; 13 patients $(68 \%)$ received ibrutinib as planned without dose reduction. The 4-week overall response rate was $83 \%$, and $61 \%$ achieved a MRD-negative marrow. In this subset, the 1-year OS and PFS were $86 \%$ and $59 \%$, respectively, with lower CRS severity and lower serum concentrations of CRS-associated cytokines, despite equivalent in vivo CART-cell expansion ${ }^{[58]}$.

\section{CAR-NK CELLS}

More recently, the early results of a phase 1 and 2 study of NK cells that were derived from cord blood and engineered to express anti-CD19 CAR, interleukin-15, and an inducible caspase 9 safety switch were published46. This therapy was tested in heavily pretreated patients with multiply relapsed or refractory CLL. At a median follow-up of 13.8 months, 4 of 5 patients with CLL had an objective response and 3 (67\%) had a complete response. Response durations cannot be assessed because of the administration of other therapies (immunomodulatory agent, chemoimmunotherapy, or allo-HSCT), starting as early as 30 days after the infusion of CAR-NK cells. The infused CAR-NK cells persisted at low levels for at least 12 months, despite the substantial HLA mismatch between the infused NK cells and the recipient. The 
inclusion of interleukin-15 in the construct may have played an important role in the persistence and antitumor activity of these CAR-NK cells. Allogeneic CARNK cells can be delivered in adoptive transfer without the serious cytokine release syndrome, GVHD, or neurologic toxic effects that have been associated with CAR T-cell therapy ${ }^{[59,60]}$ Besides, this technique may become accessible to many patients with $R / R$ CLL due to the minimal HLA-matching requirements between the donor of CAR-NK cells and the patient and the possibility to produce more than 100 doses of CAR-NK cells from a single cord-blood unit ${ }^{[61]}$.

\section{REFERENCES}

1.Gonçalves MV, Rodrigues CA, Lorand Metze IGH, et al. Chronic lymphocytic leukemia in Brazil: A retrospective analysis of 1903 cases. Am. J. Hematol; v. 92, n. 8, p. E 171- E173, 2017.

2.Hallek $M$, Cheson BD, Catovsky $D$, et al. iwCLL guidelines for diagnosis, indications for treatment, response assessment, and supportive management of CLL. Blood; v. 131, n.25, p. 27452760, 2018.

3.Byrd JC, Brown JR, O'Brien S, et al. Ibrutinib versus Ofatumumab in Previously Treated Chronic Lymphoid Leukemia. N. Engl. J; Med; v. 371, n.3, p. 213-223, 2014.

4.Burger JA, Tedeschi A, Barr PM, et al. Ibrutinib as Initial Therapy for Patients with Chronic Lymphocytic Leukemia. N. Engl. J. Med; v. 371, n.3, p. 2425-2437, 2015.

5.Barr PM, Robak T, Owen C, et al. Sustained efficacy and detailed clinical follow-up of first-line ibrutinib treatment in older patients with chronic lymphocytic leukemia: extended phase 3 results from RESONATE-2. Haematologica; v.103, n. 9, p.2018.

6.Byrd JC, Hillmen P, O'Brien S, et al. Long-term follow-up of the RESONATE phase 3 trial of ibrutinib vs ofatumumab. Blood; v. 133, n. 19, p. 1502-1510, 2019.

7.Sharman JP, Coutre SE, Furman RR, et al. Final Results of a Randomized, Phase III Study of Rituximab With or Without Idelalisib Followed by Open-Label Idelalisib in Patients With Relapsed Chronic Lymphocytic Leukemia. J. Clin. Oncol; v. 37, n. 16, p. 2031-2042, 2019.

\section{CONCLUSIONS}

Although allo-HSCT in CLL is decreasing in developing countries, in Brazil we may still consider allo-HSCT as an option in lower transplant risk patients, mainly due to inaccessibility of new agents in the public system in patients with relapse/ refractory disease. However, if new agents are available, allo-HSCT should be reserved for high-risk patients and/or relapsed / refractory disease after treatment failure with BCL-2 inhibitor and/or BTK inhibitors. Besides, clinicians should always consider including their patients in this scenario in clinical trials.

8.Seymour JF, Kipps TJ, Eichhorst B, et al. Venetoclax-Rituximab in Relapsed or Refractory Chronic Lymphocytic Leukemia. N. Engl. J. Med; v. 378, n. 12, p. 1107-1120, 2018.

9.Fischer K, Al-Sawaf O, Bahlo J, et al. Venetoclax and Obinutuzumab in Patients with CLL and Coexisting Conditions. N. Engl. J. Med; v.380, n.23, p. 2225-2236, 2019.

10.Shanafelt T. Treatment of older patients with chronic lymphocytic leukemia: key questions and current answers. Hematology; n. 1, p. 158167, 2013.

11.Kharfan-Dabaja MA, Pidala J, Kumar A, Terasawa T, Djulbegovic B. Comparing efficacy of reduced-toxicity allogeneic hematopoietic cell transplantation with conventional chemo-(immuno) therapy in patients with relapsed or refractory CLL: a Markov decision analysis. Bone Marrow Transplant; v.47, n. 9, p. 2012.

12.Gribben JG. How and when I do allogeneic transplant in CLL. Blood; v. 132, n. 1, p. $1164-$ 1170, 2018.

13.Dreger P, Corradini P, Kimby E, et al. Indications for allogeneic stem cell transplantation in chronic lymphocytic leukemia: The EBMT transplant consensus. Leukemia; v. 21, n. 1, p. 2007.

14.Furman RR, Sharman JP, Coutre SE, et al. Idelalisib and rituximab in relapsed chronic lymphocytic leukemia. N. Engl. J. Med. 2014;370(11):997-1007.

15.Burger JA, Tedeschi A, Barr PM, et al. Ibrutinib as Initial Therapy for Patients with Chronic Lymphocytic Leukemia. N. Engl. J. Med; v. 373, n.25, p.2015. 
16.Kharfan-Dabaja MA, Kumar A, Hamadani M, et al. Clinical Practice Recommendations for Use of Allogeneic Hematopoietic Cell Transplantation in Chronic Lymphocytic Leukemia on Behalf of the Guidelines Committee of the American Society for Blood and Marrow Transplantation. Biol. Blood Marrow Transplant; v. 22, n. 12, 2117-2125, 2016.

17.Roeker LE, Dreger P, Brown JR, et al. Allogeneic stem cell transplantation for chronic lymphocytic leukemia in the era of novel agents. Blood Adv; v.4, n. 16 p. 3977-3989, 2020.

18.Gribben JG, Zahrieh D, Stephans K, et al. Autologous and allogeneic stem cell transplantations for poor-risk chronic lymphocytic leukemia. Blood; v.106, n. 13, p. 4389-4396, 2005.

19.Malhotra P, Hogan WJ, Litzow MR, et al. Longterm outcome of allogeneic stem cell transplantation in chronic lymphocytic leukemia: analysis after a minimum follow-up of 5 years. Leuk. Lymphoma; v. 49, n.9. p. 1724-1730, 2008.

20.Sorror ML, Maris MB, Sandmaier BM, et al. Hematopoietic Cell Transplantation After Nonmyeloablative Conditioning for Advanced Chronic Lymphocytic Leukemia. J. Clin. Oncol. v.23, n.15, p. 3819-3829, 2005.

21.Sorror $\mathrm{ML}$, Storer $\mathrm{BE}$, Sandmaier BM, et al. Five-Year Follow-Up of Patients With Advanced Chronic Lymphocytic Leukemia Treated With Allogeneic Hematopoietic Cell Transplantation After Nonmyeloablative Conditioning. J. Clin. Oncol; v.26, n.30, p. 4912-4920. 2008.

22. Herth I, Dietrich S, Benner A, et al. The impact of allogeneic stem cell transplantation on the natural course of poor-risk chronic lymphocytic leukemia as defined by the EBMT consensus criteria: a retrospective donor versus no donor comparison. Ann. Oncol; v.25, n.1, p. 200-206, 2014.

23.Poon ML, Fox PS, Samuels Bl, et al. Allogeneic stem cell transplant in patients with chronic lymphocytic leukemia with $17 p$ deletion: consult-transplant versus consult- no-transplant analysis. Leuk. Lymphoma; 56, n. 3, p. 711-715, 2015.

24.Dreger $\mathrm{P}$, Döhner $\mathrm{H}$, Ritgen $\mathrm{M}$, et al. Allogeneic stem cell transplantation provides durable disease control in poor-risk chronic lymphocytic leukemia: long-term clinical and MRD results of the German CLL Study Group CLL3X trial. Blood; v.14, 2438-2447, 2010.
25.Dreger P, Schnaiter A, Zenz T, et al. TP53, SF3B1, and NOTCH1 mutations and outcome of allotransplantation for chronic lymphocytic leukemia: six-year follow-up of the GCLLSG CLL3X trial. Blood; v.14, p. 3284-3288, 2013.

26.Krämer I, Stilgenbauer S, Dietrich S, et al. Allogeneic hematopoietic cell transplantation for high-risk CLL: 10-year follow-up of the GCLLSG CLL3X trial. Blood; v. 130, n. 12, p. 1477-1480, 2017.

27.Khouri IF, Bassett R, Poindexter N, et al. Nonmyeloablative allogeneic stem cell transplantation in relapsed/refractory chronic lymphocytic leukemia. Cancer; v. 117, n. 20. p. 4679-4688, 2011.

28.Khouri IF, Wei W, Korbling M, et al. BFR (bendamustine, fludarabine, and rituximab) allogeneic conditioning for chronic lymphocytic leukemia/ lymphoma: reduced myelosuppression and GVHD. Blood; v.q124, n.14, p. 2306-2312, 2014.

29.van Gorkom G, van Gelder M, Eikema D-J, et al. Outcomes of haploidentical stem cell transplantation for chronic lymphocytic leukemia: a retrospective study on behalf of the chronic malignancies working party of the EBMT. Bone Marrow Transplant; v. 53, n.3, p. 255-256, 2018.

30.Xavier E, Cornillon J, Ruggeri A, et al. Outcomes of Cord BloodTransplantation Using Reduced-Intensity Conditioning for Chronic Lymphocytic Leukemia: A Study on Behalf of Eurocord and Cord Blood Committee of Cellular Therapy and Immunobiology Working Party, Chronic Malignancies Working Party of. Biol. Blood Marrow Transplant; v.21, n.8, p. 1515-1523, 2015.

31.Fuchs EJ. HLA-haploidentical blood or marrow transplantation with high-dose, post-transplantation cyclophosphamide. Bone Marrow Transplant; v.50, n.s2, p. S31-S36, 2015.

32.Luznik L, O'Donnell P V., Symons HJ, et al. HLA-Haploidentical Bone Marrow Transplantation for Hematologic Malignancies Using Nonmyeloablative Conditioning and High-Dose, Posttransplantation Cyclophosphamide. Biol. Blood Marrow Transplant; v.14, n.6, p. 641-650, 2008.

33.Brunstein CG, Barker JN, Weisdorf DJ, et al. Umbilical cord blood transplantation after nonmyeloablative conditioning: impact on transplantation outcomes in 110 adults with hematologic disease. Blood; v.110, n.8, p. 3064-3070, 2007. 
34.Michallet $M$, Dreger $P$, Sutton L, et al. Autologous hematopoietic stem cell transplantation in chronic lymphocytic leukemia: results of European intergroup randomized trial comparing autografting versus observation. Blood; v. 117,n.5, p. 1516-1521, 2011.

35.de Wreede LC, Watson M, van Os M, et al. Improved relapse-free survival after autologous stem cell transplantation does not translate into better quality of life in chronic lymphocytic leukemia: Lessons from the randomized European Society for Blood and Marrow Transplantation-Intergroup study. Am. J. Hematol.

36.Sutton L, Chevret S, Tournilhac O, et al. Autologous stem cell transplantation as a first-line treatment strategy for chronic lymphocytic leukemia: a multicenter, randomized, controlled trial from the SFGM-TC and GFLLC. Blood; v.17, n.23, p. 6109-6119, 2011.

37.Rozovski U, Benjamini O, Jain $\mathrm{P}$, et al. Outcomes of Patients With Chronic Lymphocytic Leukemia and Richter's Transformation After Transplantation Failure. J. Clin. Oncol; v. 33, v. 14, p. 15571563, 2015.

38.Coutre SE, Byrd JC, Hillmen P, et al. Long-term safety of single-agent ibrutinib in patients with chronic lymphocytic leukemia in 3 pivotal studies. Blood Adv; v. 3. n. 12, p. 1799-1807, 2019.

39. Coutre S, Choi M, Furman RR, et al. Venetoclax for patients with chronic lymphocytic leukemia who progressed during or after idelalisib therapy. Blood; v. 131, n.15, p. 1704-1711, 2018.

40.Ryan CE, Sahaf B, Logan AC, et al. Ibrutinib efficacy and tolerability in patients with relapsed chronic lymphocytic leukemia following allogeneic HCT. Blood; v. 128, n. 25, 2016.

41.Richardson SE, Khan I, Rawstron A, et al. Risk-stratified adoptive cellular therapy following allogeneic hematopoietic stem cell transplantation for advanced chronic lymphocytic leukaemia. Br. J. Haematol; v. 50, n. 10, p. $640-$ 648, 2013.

42.Hahn M, Böttcher S, Dietrich S, et al. Allogeneic hematopoietic stem cell transplantation for poor-risk CLL: dissecting immune-modulating strategies for disease eradication and treatment of relapse. Bone Marrow Transplant. v.50, n.10, p. 1279-1285, 2015.
43.Mehta J, Powles R, Singhal S, et al. Clinical and hematologic response of chronic lymphocytic and prolymphocytic leukemia persisting after allogeneic bone marrow transplantation with the onset of acute graft-versus-host disease: possible role of graft-versus-leukemia. Bone Marrow Transplant; v.17, n.3, p.371-5, 1996.

44.Porter DL, Hwang W-T, Frey N V., et al. Chimeric antigen receptor $T$ cells persist and induce sustained remissions in relapsed refractory chronic lymphocytic leukemia. Sci. Transl. Med. v. 7, n.303, p. 139ra-303ra, 2015.

45.Turtle CJ, Hay KA, Hanafi L-A, et al. Durable Molecular Remissions in Chronic Lymphocytic Leukemia Treated With CD19-Specific Chimeric Antigen Receptor-Modified T Cells After Failure of Ibrutinib. J. Clin. Oncol; v. 35, p. 26, p. 3010-3020, 2017.

46.Liu E, Marin D, Banerjee $P$, et al. Use of CAR-Transduced Natural Killer Cells in CD19-Positive Lymphoid Tumors. N. Engl. J. Med; v. 382, n.6. p. 545-553, 2020.

47.Tournilhac O, Le Garff-Tavernier M, Nguyen Quoc S, et al. Efficacy of minimal residual disease driven immune-intervention after allogeneic hematopoietic stem cell transplantation for high-risk chronic lymphocytic leukemia: results of a prospective multicentric trial. Haematologica. 2020; haematol.2019.239566.

48. Michallet $M$, Dreger $P$, Sobh $M$, et al. Ibrutinib as a salvage therapy after allogeneic HCT for chronic lymphocytic leukemia. Bone Marrow Transplant; v. 55, n. 5, p. 884-890, 2020.

49.Niemann CU, Herman SEM, Maric I, et al. Disruption of in vivo Chronic Lymphocytic Leukemia Tumor-Microenvironment Interactions by lbrutinib - Findings from an Investigator-Initiated Phase II Study. Clin. Cancer Res; v. 22, n. 7, p. 1572-1547, 2016.

50.Bachireddy P, Wu CJ. Arresting the Inflammatory Drive of Chronic Lymphocytic Leukemia with Ibrutinib. Clin. Cancer Res; v. 22, n. 7, p. 15471549, 2016.

51.Miklos D, Cutler CS, Arora M, et al. Ibrutinib for chronic graft-versus-host disease after failure of prior therapy. Blood; v. 130, n. 21, p. 2243-2250. 2017.

52.Schutt SD, Fu J, Nguyen $\mathrm{H}$, et al. Inhibition of BTK and ITK with Ibrutinib Is Effective in the Pre- 
vention of Chronic Graft-versus-Host Disease in Mice. PLoS One; v. 10, n. 11, p. 2015.

53.Dubovsky JA, Flynn R, Du J, et al. Ibrutinib treatment ameliorates murine chronic graft-versus-host disease.J. Clin. Invest; v. 124, n. 11, p. 4867-4876, 2014.

54.Kochenderfer JN, Dudley ME, Kassim SH, et al. Chemotherapy-Refractory Diffuse Large B-Cell Lymphoma and Indolent B-Cell Malignancies Can Be Effectively Treated With Autologous T Cells Expressing an Anti-CD19 Chimeric Antigen Receptor. J. Clin. Oncol; v. 33, n. 6, p. 540-549, 202540-549, 2015.

55.Lemal R, Tournilhac O. State-of-the-art for CAR T-cell therapy for chronic lymphocytic leukemia in 2019. J. Immunother. Cancer; v. 7, n.1, p. , 2019.

56.Neelapu SS, Locke FL, Bartlett NL, et al. Axicabtagene Ciloleucel CAR T-Cell Therapy in Refractory Large B-Cell Lymphoma. N. Engl. J. Med; v. 377, n. 26, p. p. 2531-2544, 2017.

57.Schuster SJ, Svoboda J, Chong EA, et al. Chimeric Antigen Receptor T Cells in Refractory
B-Cell Lymphomas. N. Engl. J. Med; v. 377, n. 26, p. 2545-2554, 2017.

58.Gauthier J, Hirayama A V., Purushe J, et al. Feasibility and efficacy of CD19-targeted CAR T cells with concurrent ibrutinib for CLL after ibrutinib failure. Blood; v. 135, n. 19, p. 1650-1660, 2020.

59.Miller JS, Soignier Y, Panoskaltsis-Mortari A, et al. Successful adoptive transfer and in vivo expansion of human haploidentical NK cells in patients with cancer. Blood; v.105, v. 8, p. 30513057, 2005.

60.Ruggeri L, Mancusi A, Burchielli E, et al. NK cell alloreactivity and allogeneic hematopoietic stem cell transplantation. Blood Cells, Mol. Dis; v. 40, n. 1. p. 84-90, 2008.

61.Liu E, Tong Y, Dotti G, et al. Cord blood NK cells engineered to express IL-15 and a CD19-targeted CAR show long-term persistence and potent antitumor activity. Leukemia; v. 32, n. 2, p. $520-531,2018$ 